\title{
Catalytic oxidation of Methyl Orange by an amorphous FeOOH catalyst developed from a high iron-containing fly ash
}

\author{
Yi Li, Fu-Shen Zhang* \\ Research Center for Eco-Environmental Sciences, Chinese Academy of Sciences, 18 Shuangqing Road, Beijing 100085, China
}

\section{A R T I C L E I N F O}

\section{Article history:}

Received 11 August 2009

Received in revised form 7 December 2009

Accepted 12 December 2009

\section{Keywords:}

Photo-Fenton

Fly ash

$\mathrm{UV} / \mathrm{H}_{2} \mathrm{O}_{2}$

Mesoporous structure

Amorphous $\mathrm{FeOOH}$

\begin{abstract}
A B S T R A C T
Heterogeneous photo-Fenton process using an amorphous $\mathrm{FeOOH}$ as catalyst was studied to degrade Methyl Orange (MO) dye in aqueous solution. The amorphous FeOOH was prepared by dissolution and precipitation using a high iron-containing fly ash as raw material. The ash not only provided iron source but also acted as a supporter of amorphous $\mathrm{FeOOH}$. Coating the fly ash particles with the amorphous FeOOH significantly enhanced the removal of $\mathrm{MO}$, and $2.5 \mathrm{~g}$ of catalyst was sufficient to degrade $50 \mathrm{mg} \mathrm{MO}$ from $1 \mathrm{l}$ of aqueous solution at $\mathrm{pH} 7.0$ after $80 \mathrm{~min}$. Oxidant concentration, solution $\mathrm{pH}, \mathrm{UV} / \mathrm{dark} / \mathrm{sunlight}$ and recycling of the catalyst were investigated in order to evaluate the photo-Fenton effects. Moreover, variations of particle size before and after preparation, separation of solid-liquid and stability of the amorphous $\mathrm{FeOOH}$ in the catalyst were studied. It was testified that the amorphous $\mathrm{FeOOH}$ on the surface of fly ash was stable and the Fenton catalyst was easily separated from the aqueous system.
\end{abstract}

(c) 2009 Elsevier B.V. All rights reserved.

\section{Introduction}

The Fenton reaction has its own unique advantage in the degradation of pollutants as one of advanced oxidation processes (AOPs) because its reagents are environmentally benign, cheap and relatively easy to obtain and handle. The traditional homogeneous Fenton reaction works only in the $\mathrm{pH}$ range of 2.0-4.0 and tends to be highest at around $\mathrm{pH} 3.0$ and then decreased with increasing $\mathrm{pH}$, for example, the Fenton process nearly comes to halt as the $\mathrm{pH}$ increases from 3.0 to 7.0 when $p$-hydroxybenzoic acid was degraded in the system of homogenous Fenton [1]. For overcoming the above disadvantages of the homogeneous Fenton process, the heterogeneous Fenton reaction with aid of light irradiation was developed.

According to previous studies, some crystalline iron hydroxides/oxides $\left(\alpha-\mathrm{FeOOH}, \gamma\right.$-FeOOH and $\left.\gamma-\mathrm{Fe}_{2} \mathrm{O}_{3}\right)$ [2-5] and supported iron compounds [6-10] as photo-Fenton catalysts have been intensively studied and are thought to be promising effective catalysts in the heterogeneous system. Briefly, their effectiveness is attributed to the production of surface iron complex (e.g. surface Fe (IV) species) and hydroxyl radicals (HO•) when UV irradiation of the surface broke chemical bond. Then the highly oxidized and unstable surface iron complex reacts with water to form a further $\mathrm{HO}^{\bullet}$ [2]. Thus, the catalyst experiences an iron cycling on the surface without significant diffusion into the solution phase.

\footnotetext{
* Corresponding author. Tel.: +86 10 62849515; fax: +861062849515.

E-mail address: fszhang@rcees.ac.cn (F.-S. Zhang).
}

The free hydroxyl radicals are powerful, non-selective oxidants with the ability of decomposing almost all organic contaminants into carbon dioxide and water in aqueous solution, including dyes [8-10].

To our knowledge, however, amorphous FeOOH used as photoFenton reagent has not been attempted to degrade pollutants although its surface area is higher than the crystalline iron hydroxides. That is because the amorphous $\mathrm{FeOOH}$ is merely available as fine powder or exists as gel or suspension in the solution, hence it is difficult to be separated entirely from the solution. Another shortage of amorphous $\mathrm{FeOOH}$ is that it tends to form crystalline iron oxides in the preparation process, which may greatly reduce its degradation capacity since its surface area is greatly diminished, thus a stable and easily separated amorphous FeOOH photo-Fenton catalyst is desired.

The aim of this study was to investigate an amorphous $\mathrm{FeOOH}$ photo-Fenton reagent prepared by a high iron-containing fly ash (HICFA). The iron oxide content in this fly ash was as high as $17.52 \%$ and the amorphous $\mathrm{FeOOH}$ supported on the fly ash particles was prepared by the rearrangement of iron oxide contained in the fly ash.

Wastewater released from textile, painting, leather, printing and photography industries contains some recalcitrant pollutants, especially synthetic dyes, and the presence of small amounts of dyes (below $1 \mathrm{ppm}$ ) is clearly visible, and greatly influences the water environment [11]. Besides the aesthetic problem, dyes in wastewater limit the possible use of water and reduce the efficacy of the microbial wastewater treatment because they may be toxic to microorganisms. In this study, Methyl Orange (MO, Scheme 1) dye was selected as a model hydrocarbon due to its environmen- 


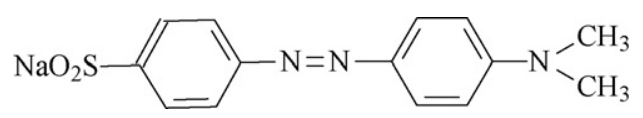

Scheme 1. Molecular structure of MO.

tal significance, ease of analysis, and relative solubility in water. The effects of important variables on the degradation of MO were investigated. This study was more concerned about the operational performance of the amorphous $\mathrm{FeOOH}$ photo-Fenton reagent for treating the wastewater, so the solid-liquid separation, variations of particle size before and after preparation, stability of amorphous $\mathrm{FeOOH}$ and recycling efficiency were investigated in detail.

\section{Experimental details}

\subsection{Materials}

Fly ash, a byproduct from power station, is one of the industry solid wastes in China, and the high iron-containing fly ash in this study was sampled from Gaobeidian thermal power plant $(4 \mathrm{MW} \times 200 \mathrm{MW})$ located in Beijing (China). The ash was collected by an electrostatic precipitator after the pulverized coal burnt in the cyclone furnace boiler. The fly ash contains element oxides such as $\mathrm{SiO}_{2} 29.33 \%, \mathrm{Al}_{2} \mathrm{O}_{3} 25.70 \%, \mathrm{Fe}_{2} \mathrm{O}_{3} 17.52 \%, \mathrm{CaO} 22.17 \%, \mathrm{MgO} 1.60 \%$, $\mathrm{SO}_{3} 4.15 \%, \mathrm{~K}_{2} \mathrm{O} 0.56 \%, \mathrm{Na}_{2} \mathrm{O} 1.81 \%$ and its Loss on Ignition (LOI) is $0.27 \%$.

$\mathrm{MO}, \mathrm{H}_{2} \mathrm{O}_{2}$ (30\%), $\mathrm{FeCl}_{3}$ (AR) and diethyl ether (AR) were purchased from Beijing chemical works. Stocking solution containing $1000 \mathrm{mg} \mathrm{l}^{-1}$ of MO was directly dissolved from pure MO, and MO working solutions were freshly made by diluting stocking solution with distilled water. $\mathrm{HCl}(1 \mathrm{M}, 0.1 \mathrm{M})$, and $\mathrm{NaOH}(1 \mathrm{M}, 0.1 \mathrm{M})$ solutions were prepared for $\mathrm{pH}$ adjustment.

\subsection{Preparation of photo-Fenton catalyst and analysis methods}

The photo-Fenton catalyst was prepared by dissolution and precipitation using the high iron-containing fly ash as the raw material. The element Fe in the fly ash was dissolved into the acidic solution, then precipitated as the amorphous $\mathrm{FeOOH}$ and simultaneously deposited on the surface of the residual ash particles. The detailed depiction of synthesis process was presented in a previous report [12]. Briefly, the catalyst powder was prepared according to the following procedure: firstly, $3.0 \mathrm{~g}$ of the raw fly ash was added into $250 \mathrm{ml}$ of water, and the mixture was stirred and heated to $95^{\circ} \mathrm{C}$ for $1 \mathrm{~h}$ to remove some alkali and alkaline earth elements in the fly ash, then the insoluble material was filtrated and dried at $100{ }^{\circ} \mathrm{C}$ for $2 \mathrm{~h}$. Secondly the pretreated fly ash was contacted with $100 \mathrm{ml}$ of $1 \mathrm{M} \mathrm{HCl}$ solution, vibrated $(200 \mathrm{r} / \mathrm{min}$ ) in a rotary shaker (THZ-100, Nanjing chemical apparatus Inc, China) for $2 \mathrm{~h}$ and placed steadily at $60^{\circ} \mathrm{C}$ for $0.5 \mathrm{~h}$. Thirdly, $1 \mathrm{M} \mathrm{NaOH}$ solution was added dropwise into the solution until the final $\mathrm{pH}$ was adjusted to about 6.0 (except where otherwise specified). The mixture continuously vibrated for $1 \mathrm{~h}$ and aged at $75^{\circ} \mathrm{C}$ for 3 days (except where otherwise specified). Finally, the slurry was dewatered by centrifugation and then dried at $75^{\circ} \mathrm{C}$ for $24 \mathrm{~h}$. Upon cooling, the composite solid was broken to separate the powders in the carnelian mortar, and afterwards stored in the capped polyethylene bottle for use.

The X-ray diffraction (XRD) patterns of the catalyst were obtained using X-ray diffractometer (Philips PW 1700, Holand) to examine the change of crystalline phase and the operating conditions were $45 \mathrm{kV}$ and $250 \mathrm{~mA}$, using $\mathrm{Cu} K \alpha$ radioactive source. The surface morphology was obtained using scanning electron micrograph (SEM) (Hitachi S-3000N, Japan). The technology of laser particle size (LPS) was used to analyze the particle size distribution of raw fly ash and the catalyst by laser particle sizer (Master size
2000, Malvern Co, UK). The BET (Brunauer-Emmet-Teller) specific surface area was determined by fitting the linear portion of the BET plot to BET equation, and average pore size was calculated based on the desorption plot of $\mathrm{N}_{2}$ adsorption-desorption isotherm using the Barrett-Joyner-Halenda (BJH) method (Micrometritics ASAP 2000, USA). The absorbance of MO solution was examined by the UV-vis spectroscopy (UV-2450, Shimadzu, Japan). The iron leaching iron concentration was examined by inductively coupled plasma optical emission spectrometer (ICP-OES) (PerkinElmer OPTIMA 2000, USA).

\subsection{Experimental procedure of photo-Fenton degradation of $M O$}

The UV degradation experiments were carried out inside a $600 \mathrm{~m} \times 550 \mathrm{~mm} \times 450 \mathrm{~mm}$ stainless box with a door in one side for operating. A UV lamp (GY-250, TIANMEI light source of Beijing, China) with the main emission of $365 \mathrm{~nm}$ positioned in the center of reactor was used as an irradiation source, and a series of 100$\mathrm{ml}$ quartz flasks were employed as photo-Fenton reaction vessels. About $21 \mathrm{~cm}^{2}$ of surface area in the flasks was directly exposed to the irradiation light, and the photo flux near the flasks was about $60 \mathrm{~W} \mathrm{~m}^{-2}$ (UVA radiation meter, photoelectric instrument factory of Beijing Normal University, China). The flasks were stirred magnetically during irradiation. In the experiments, the effects of solution $\mathrm{pH}$ (from 5.0 to 7.0), contact time (from 120 to $180 \mathrm{~min}$ ), irradiation light (sunlight, darkness, UV) and $\mathrm{H}_{2} \mathrm{O}_{2}$ concentration $(0,5.26,15.8$ and $26.3 \mathrm{mM})$ were examined so as to optimize operation conditions. The solution was sampled and taken out from the reactor at desired time intervals, and then centrifuged to separate solid from the solution. For avoiding any possible effect of further reaction caused by the $\mathrm{HO}^{\bullet}$ after centrifugation, the supernatant was analyzed immediately by UV-vis spectroscopy to test the degradation of MO.

The wavelength of $460.5 \mathrm{~nm}$, which is the maximum absorbance wavelength registered experimentally and is ascribed to the azo bond $(-N \equiv N-)$ of the Methyl Orange molecule, was used for evaluation of the MO photodegradation. The photocatalytic degradation conversion was calculated with the following formula without concerning the degradation intermediates,

$\eta_{\mathrm{D}}=\frac{\mathrm{Abs}_{0}-A b s_{t}}{\mathrm{Abs}_{0}} \times 100 \%$

where $\eta_{\mathrm{D}}$ is the degradation ratio of $\mathrm{MO}, \mathrm{Abs}_{0}$ and $\mathrm{Abs}_{t}$ are the absorbency of MO solution at initial time and after irradiated in $t$ time at $460.5 \mathrm{~nm}$, respectively. Moreover, the experimental data are fitted by applying a pseudo-first-order model $\ln \left(\mathrm{Abs}_{t} / \mathrm{Abs}_{0}\right)=-k t$ to determine an observed rate constant $(k)$ of MO in the experiments.

In addition, the solar induced oxidation of MO was performed at Research Center for Eco-Environmental Sciences (RCEES) parking lot $\left(39^{\circ} 48^{\prime} \mathrm{N} ; 116^{\circ} 28^{\prime} \mathrm{E}\right)$, Chinese Academy of Science (CAS) in Beijing, China. The environmental temperature in the experimental time was $15-18^{\circ} \mathrm{C}$, and the reaction temperature was controlled at $25^{\circ} \mathrm{C}$. The solar irradiation intensity was in range of $540-600 \mathrm{~W} \mathrm{~m}^{-2}$ with an average UV irradiation intensity $6 \mathrm{~W} \mathrm{~m}^{-2}$. Darkness was realized by wrapping the flask using aluminum foils.

\section{Results and discussion}

\subsection{Characterization of the catalyst}

The SEM image of the catalyst is shown in Fig. 1. The amorphous FeOOH loaded on the sphere was irregular porous structure, and the size of catalyst mainly ranged from 15 to $30 \mu \mathrm{m}$. The inner sphere in the catalyst was the residual fly ash after acidized by $\mathrm{HCl}$ solution and then coated by the amorphous $\mathrm{FeOOH}$ when iron precipitated from solution. So the high iron-containing fly ash not 


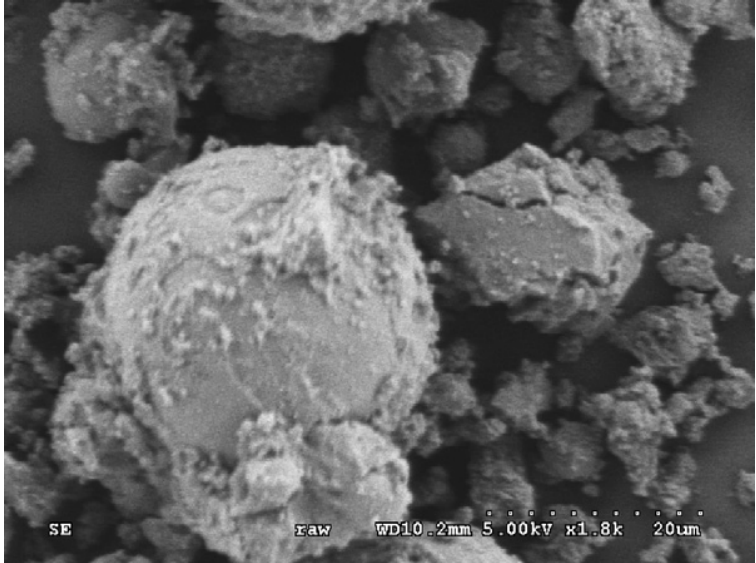

Fig. 1. SEM image of the amorphous FeOOH supported on the fly ash.

only provided iron source in the synthesis process but also worked as the supporter of amorphous $\mathrm{FeOOH}$. Moreover, no crystalline $\mathrm{FeOOH}$ was found in the image of XRD. The average pore size of catalyst is $23 \AA$ and its BET specific surface area is $140 \mathrm{~m}^{2} / \mathrm{g}$. More detailed properties of IR, XRD, porosity, pore distribution and the other information were shown elsewhere [12].

\subsection{Effects of the photo-Fenton experiments}

Due to the dissolution of the solid catalyst in acidic water to produce ferrous ions in heterogeneous system, the catalyst will inevitably increase the catalytic efficiency of MO when the $\mathrm{pH}$ was adjusted to below 3.0 [13], moreover Chou et al. [4] also reported that the homogeneous catalysis was insignificant at $\mathrm{pH}>4.4$ when oxidizing Benzoic acid using $\gamma$-FeOOH catalyst because the dissolved iron concentrations were very low. For enhancing catalysis, UV light was introduced into the heterogeneous Fenton system at a higher $\mathrm{pH}$. In our study, in order to evaluate the contribution of UV light to the heterogeneous Fenton when the solution is neutral or alkaline, the solar and dark Fenton were also studied.

The MO concentration hardly declined with only UV irradiation in the absence of $\mathrm{H}_{2} \mathrm{O}_{2}$ or catalyst, indicating that the degradation of MO by photolysis was very weak and negligible. Fig. 2(a) shows the changes of MO under the conditions of darkness, solar and ultraviolet irradiation with $\mathrm{H}_{2} \mathrm{O}_{2}$ at initial $\mathrm{pH}$ 7.0. Both removals of $\mathrm{MO}$ in the system by darkness and sunlight irradiation within 120 min fluctuated from 6.0 to $11.0 \%$ which were attributed to the adsorption of the catalyst and possible homogeneous process, and the fluctuation of removal would be ascribed the unbalanced adsorption-desorption between the MO molecule and the catalyst. Meanwhile it indicates that the sunlight was not enough to promote the catalytic process when the solution is neutral, which was not as effective as Fenton reaction in the acidic solution [14]. On the other hand, $2.5 \mathrm{~g}$ of catalyst was sufficient to degrade $50 \mathrm{mg}$ of MO from 11 of aqueous solution after $80 \mathrm{~min}$ UV irradiation. The high degradation should be ascribed to the utilization of UV light with the high irradiation intensity, moreover after the catalytic process was initiated by the UV light, the combined effect of adsorption [12] and high interface area of the catalyst could also enhance the Fenton process.

The influence of oxidant concentration on the heterogeneous photo-Fenton degradation of MO by the amorphous FeOOH was tested by adding different concentrations of hydrogen peroxide $(0,5.26,15.8$ and $26.3 \mathrm{mM})$. Fig. 2 (b) shows that the equilibrium removal ratio was about $6 \%$ after 120 min without addition of hydro peroxide, which was attributed to the adsorption of the catalyst. Nevertheless, when 5.26, 15.8 and $26.3 \mathrm{mM} \mathrm{H}_{2} \mathrm{O}_{2}$ were added into
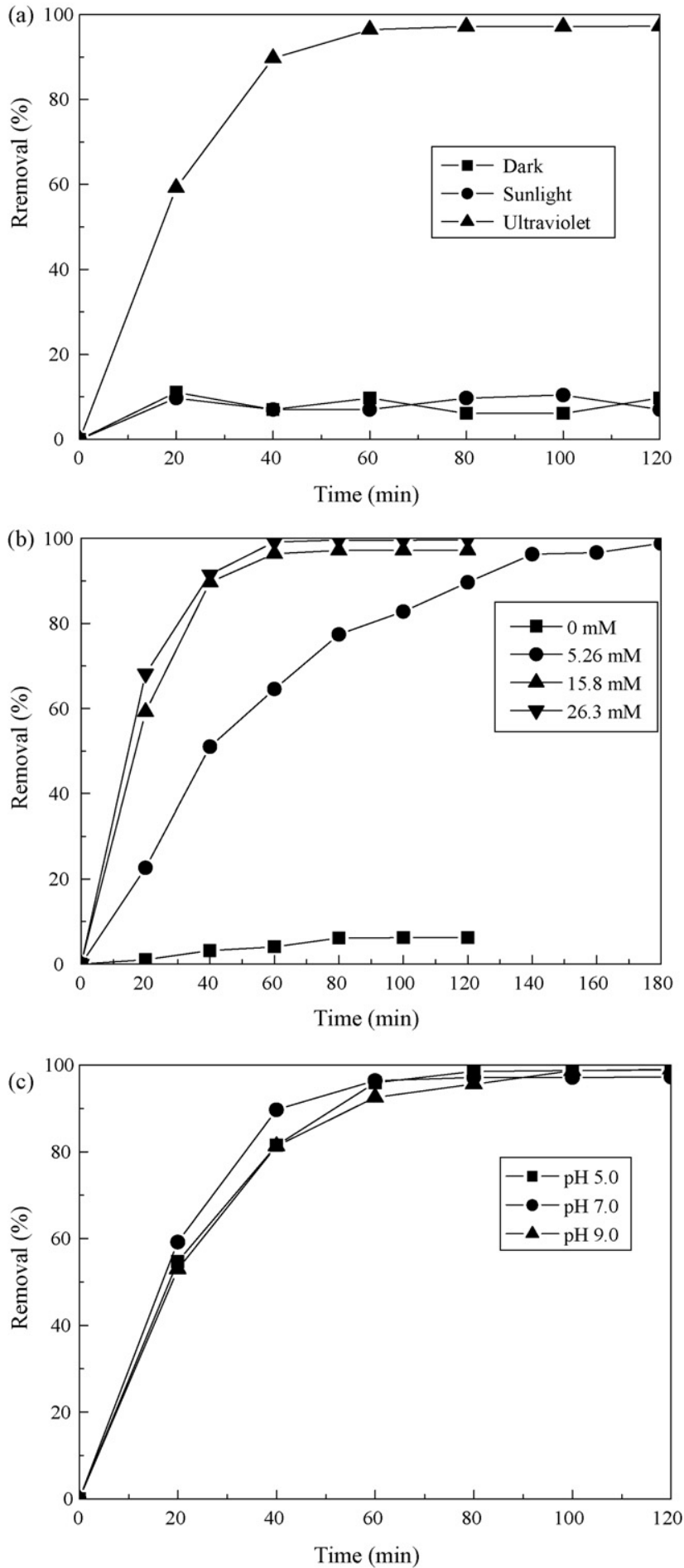

Fig. 2. Degradation of $\mathrm{MO}$ as a function of (a) light, (b) $\mathrm{H}_{2} \mathrm{O}_{2}$ and (c) pH. Experimental conditions for (a): $\mathrm{MO}$ concentration $=50 \mathrm{mgl}^{-1}$, catalyst dose $=2.5 \mathrm{gl}^{-1}, \mathrm{H}_{2} \mathrm{O}_{2}$ concentration $=15.8 \mathrm{mM}$, $\mathrm{pH} 7.0$; for (b): $\mathrm{MO}$ concentration $=50 \mathrm{mg} \mathrm{l}^{-1}$, catalyst dose $=2.5 \mathrm{gl}^{-1}, \mathrm{pH} 7.0$, light irradiation $=\mathrm{UV}$; for (c) MO concentration $=50 \mathrm{mg} \mathrm{l}^{-1}$ catalyst dose $=2.5 \mathrm{~g} \mathrm{l}^{-1}, \mathrm{H}_{2} \mathrm{O}_{2}$ concentration $=15.8 \mathrm{mM}$, and light irradiation $=\mathrm{UV}$.

the solution as oxidants, the photodegradations of MO after $20 \mathrm{~min}$ irradiation enhanced to $22.6 \%, 59.2 \%$ and $68.0 \%$, respectively, which indicated an increase of MO conversion with increasing oxidant concentrations. After $60 \mathrm{~min}$ irradiation, the solution of MO in the higher oxidant concentration (15.8 and $26.3 \mathrm{mM}$ ) was decolored fully, while that in low concentration $(5.26 \mathrm{mM})$ attained only $64.5 \%$. On the other hand, when extending irradiation time 


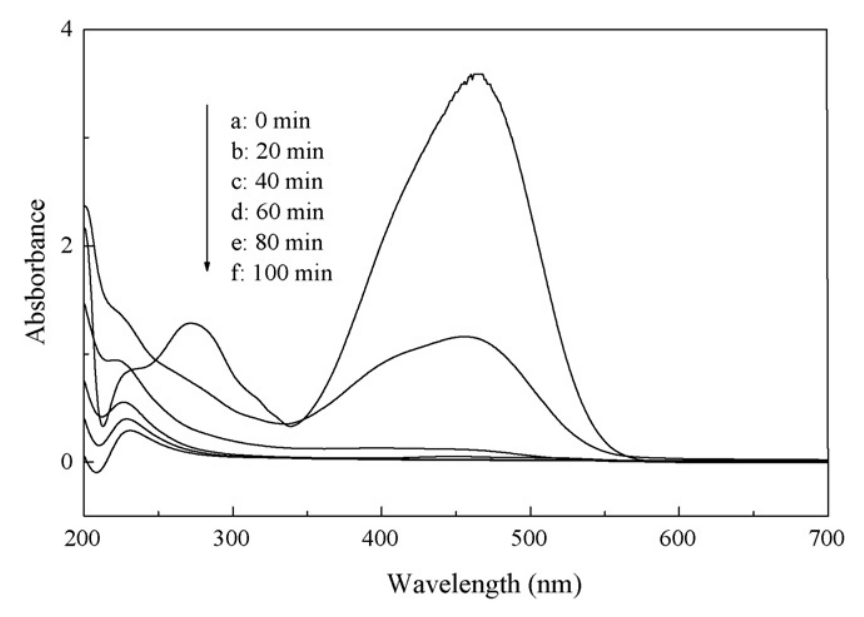

Fig. 3. UV-vis spectral changes of MO in heterogeneous UV-Fenton process. Experimental conditions: $\mathrm{MO}$ concentration $=50 \mathrm{mg} \mathrm{l}^{-1}$, catalyst dose $=2.5 \mathrm{~g} \mathrm{l}^{-1}$, and $\mathrm{H}_{2} \mathrm{O}_{2}$ concentration $=15.8 \mathrm{mM}$, $\mathrm{pH} 7.0$.

to $180 \mathrm{~min}$, the MO in the low concentration of oxidant was also photodegraded fully.

We also studied the effect of initial $\mathrm{pH}$ in the range of 5.0-9.0 and the results are presented in Fig. 2(c). In this study, all the photodegradation processes were efficient and no evident differences were seen in the $\mathrm{pH}$ range of 5.0-9.0, which greatly differs from previous results. For example, Devi et al. [15] reported that the effect of $\mathrm{pH}$ on the photodagradation of $\mathrm{MO}$ in the system of zero valent iron powder $/ \mathrm{H}_{2} \mathrm{O}_{2}$, the efficiency was halted in the $\mathrm{pH}$ range of 5.0-9.0, just like a homogeneous system. Hsueh et al. [16] also reported that the degradation rate of RB5 (Reactive Black 5) decreased sharply as the initial solution $\mathrm{pH}$ increased from 5.0 to 9.0. In addition, the removal ratios for our study after $120 \mathrm{~min}$ irradiation were above $99 \%$ within the $\mathrm{pH}$ range of 5.0-9.0. The reaction rate constants from 5.0 to 7.0 within 80 min were calculated by using a pseudo-first-order model and were 0.0489, 0.0549 and $0.0425 \mathrm{~min}^{-1}$, respectively, namely, the rapid effect of photodegradation extended to a wider alkaline range and the removal of MO show no evident decreases with increasing $\mathrm{pH}$. This observation was very important since it was previously accepted that one major drawback of the homogeneous photo-Fenton was the tight range of $\mathrm{pH}$ for its reaction.

The phenomenon that the UV-Fenton catalyst could extend the range of $\mathrm{pH}$ values for Fenton-type oxidation was also reported using iron-exchanged pillared beidellite [17] and iron-exchanged pillared bentonite [6] as the catalyst. This property should be ascribed to the acid-alkaline buffering capacities of the catalyst caused by Fe-polycations $\left[\mathrm{Fe}_{n}(\mathrm{OH})_{m}\left(\mathrm{H}_{2} \mathrm{O}\right)_{x}\right]^{(3 n-m)+}[6]$, which were intermediate derivatives between the primary hydrolyzed products and the insoluble $\mathrm{FeOOH}$. In the alkaline condition, most bases would be consumed by the Fe-polycations, and as a result, the degradation of MO could occur effectively by the UV-Fenton process just as in acidic conditions.

\subsection{UV-vis spectroscopic analysis}

Fig. 3 shows the time evolutions of the UV-vis spectra of MO during the decolorization process in the presence of the catalyst. The strong absorbance band at the visible region (at $460 \mathrm{~nm}$ ) in $\mathrm{MO}$ was attributed to a conjugated structure formed by the azo bond under the strong influence of the electron-donating dimethylamino group, and the band at $270 \mathrm{~nm}$ was ascribed to the $\pi \rightarrow \pi^{*}$ transition related to aromatic rings [18]. After $20 \mathrm{~min}$ reaction, both bands at 465 and $270 \mathrm{~nm}$ became weaker, while absorbance at a lower UV region (near $200 \mathrm{~nm}$ ) increased, due to the formation of

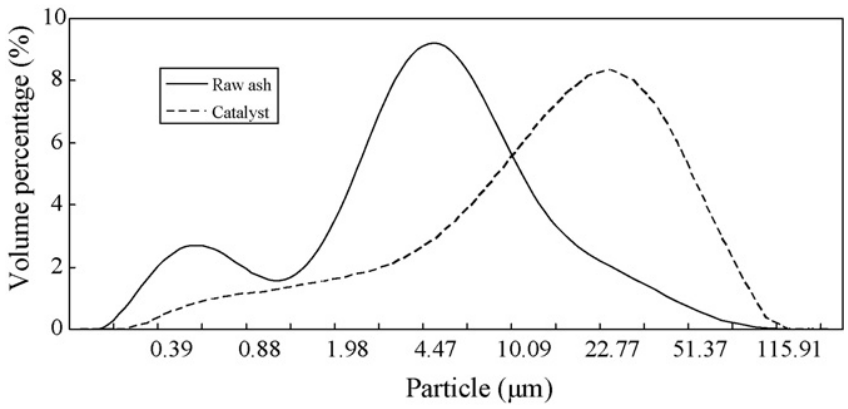

Fig. 4. Particle size distribution of the raw fly ash and the catalyst.

intermediate benzene-like organic compounds during the process of degradation [15]. Moreover, a new UV band at $226 \mathrm{~nm}$ became clear after $40 \mathrm{~min}$, which should be ascribed to sulfanilic acid-like compounds [19].

After $60 \mathrm{~min}$ of irradiation, the solution was fully decolored to transparency, and the corresponding absorbance at $460 \mathrm{~nm}$ completely disappeared in the spectrograph. Moreover, both the absorbance region near $200 \mathrm{~nm}$ and the peak at $226 \mathrm{~nm}$ also decreased, which indicates that when the intermediates of degradation in the solution accumulated to a certain concentration, the intermediates also began to degrade along with the degradation of the residual MO. In the remaining irradiation time, the absorbance region near $200 \mathrm{~nm}$ and the band at $226 \mathrm{~nm}$ continued decreasing until nearly completion, indicating that the $\mathrm{MO}$ and the intermediate species were completely degraded.

\subsection{Separation of the catalyst from the solution}

The separation of the catalyst from the solid into the liquid phase after the heterogeneous reaction is one of the important issues. Undoubtedly, the larger the powder size, the more efficient the catalyst is on the solid phase.

The particle size distributions of the raw ash and the catalyst are shown in Fig. 4, their particle size parameters and BET specific surface areas are shown in Table 1 . According to the results, the raw ash distributed in the range from 0.295 to $116 \mu \mathrm{m}$ and the catalyst was from 0.389 to $120 \mu \mathrm{m}$, correspondingly, their mean particle sizes were 5.51 and $21.1 \mu \mathrm{m}$ respectively, which indicated that the catalyst had a much bigger size than the raw ash, and its median size was nearly 4 times larger than the raw ash, thus it can efficiently accelerate separation after the photo-Fenton reaction. In a contrast experiment, equivalent raw fly ash replaced the catalyst in the solution under the same conditions. The solution was turbid and it took more than $2 \mathrm{~h}$ for the solution to become clear, but it took only several minutes for the powder of catalyst to do that.

Generally speaking, increase of particle size can reduce its specific surface area due to increase of power diameter, but in this study, specific surface area of the catalyst did not decrease, contrarily, it increased sharply. Table 1 shows that the BET surface area of the raw ash and the catalyst were 6.23 and $140 \mathrm{~m}^{2} / \mathrm{g}$, respectively. Namely, loading amorphous $\mathrm{FeOOH}$ on the surface of acidized fly ash particles increased the specific surface area by nearly 22 times

Table 1

Particle size parameters and specific surface areas of the raw ash and the catalyst.

\begin{tabular}{lllll}
\hline & $\begin{array}{l}D(10)^{\mathrm{a}}, \\
\mu \mathrm{m}\end{array}$ & $\begin{array}{l}\text { Median size } \\
D(50), \mu \mathrm{m}\end{array}$ & $\begin{array}{l}D(90)^{\mathrm{b}}, \\
\mu \mathrm{m}\end{array}$ & $\begin{array}{l}\text { BET surface area, } \\
\mathrm{m}^{2} / \mathrm{g}\end{array}$ \\
\hline Raw ash & 0.85 & 5.51 & 22.3 & 6.23 \\
Catalyst & 2.76 & 21.1 & 61.3 & 140 \\
\hline
\end{tabular}

a $D(10)$ means $10 \%$ of the powder particles are smaller than this value.

b $D(90)$ means $90 \%$ of the powder particles are smaller than this value. 


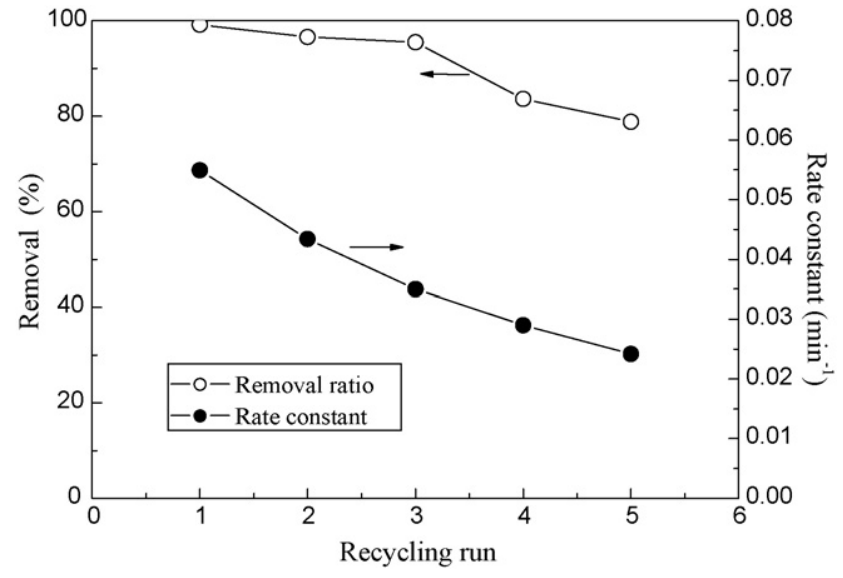

Fig. 5. Removal ratio and rate constant of five recycling runs. Experimental conditions: $\mathrm{MO}$ concentration $=50 \mathrm{mg} \mathrm{l}^{-1}$, catalyst dose $=2.5 \mathrm{gl}^{-1}, \mathrm{H}_{2} \mathrm{O}_{2}$ concentration $=15.8 \mathrm{mM}$, time $=80 \mathrm{~min}$, and $\mathrm{pH} 7.0$.

compared to the raw ash, which could be attributed to the formation of mesoporous amorphous $\mathrm{FeOOH}$. Thus it can enhance the adsorption of the catalyst and increase the interface between MO and the catalyst, thus more active surface sites of $\mathrm{Fe}(\mathrm{OH})^{2+}$ supported on the surface of fly ash are prone to contact with MO molecules and thus accelerate the photo-Fenton process.

\subsection{Recycling efficiency of the catalyst}

The recycling efficiency of the photo-Fenton reagent was tested by recycling the catalyst for decolorizing the MO dye. Experiments were carried out for $80 \mathrm{~min}$ at $\mathrm{pH}$ of 7.0 and $\mathrm{H}_{2} \mathrm{O}_{2}$ concentration of $26.3 \mathrm{mM}$. After each run, the solid powder was carefully separated from the solution, and then rinsed by $50 \mathrm{ml}$ of water and non-aqueous ether for 3 times respectively, for removing any possible remnants on the surface of catalyst. Then, fresh MO solution along with the $\mathrm{H}_{2} \mathrm{O}_{2}$ oxidant was placed in the reactor using the same catalyst powder. For the first three runs of the experiment, all MO decolorizations were above 95\% (99.2, 96.6, 95.5\% in turn), followed by a small decrease, although the rate constant of decolorization decreased steadily throughout $(0.0549,0.0434$, $0.0356 \mathrm{~min}^{-1}$ ) (Fig. 5). On the fourth and fifth runs the efficiency of the catalyst decreased to $83 \%$ and $78 \%$, respectively, with the corresponding rate constants decreasing to 0.0295 and $0.0252 \mathrm{~min}^{-1}$, which could be attributed to unavoidable leaching of iron and possible effect of contaminant adsorption on reactive sites on the catalyst surface. Nevertheless, when the reaction time prolonged to $120 \mathrm{~min}$, all MO decolorization ended up above $99 \%$.

\subsection{Stability of amorphous $\mathrm{FeOOH}$}

Pure amorphous $\mathrm{FeOOH}$ is unstable as it tends to crystallize under mild conditions, with consequent decrease in the specific surface area. Therefore, the degree of stability of the amorphous FeOOH supported on the surface of fly ash is an important property of the catalyst. For testing the stabilization of catalyst, the aging time in the synthesis was extended from 3 to 7 days and the final solution $\mathrm{pH}$ was adjusted from 3.0 to 12.0 to promote any possible nucleation of iron hydroxides/oxides, but all XRD patterns of the obtained powders showed no variation in contrast with that at the aging time of 3 days and $\mathrm{pH} 6.0$ (XRD patterns were not shown here.). It showed that amorphous $\mathrm{FeOOH}$ in the catalyst was stable and no crystalline iron oxides were formed. But when pure chemical reagents were used as the raw materials in the similar hydrothermal conditions, iron hydroxides/oxides were formed. For

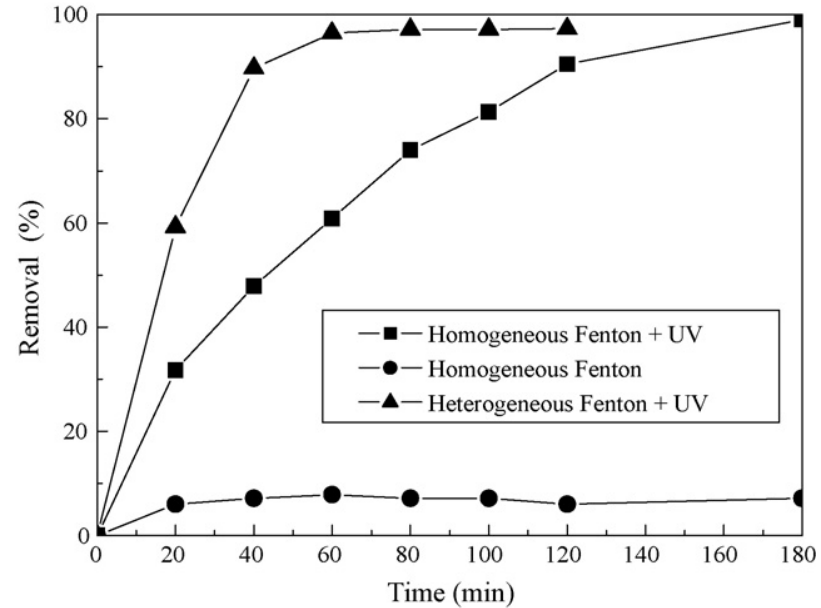

Fig. 6. Effect of homogeneous and heterogeneous catalysis on the degradation of MO. Experimental conditions for the heterogeneous Fenton: MO concentration $=50 \mathrm{mg} \mathrm{l}^{-1}$, catalyst dose $=2.5 \mathrm{~g} \mathrm{l}^{-1}, \mathrm{H}_{2} \mathrm{O}_{2}$ concentration $=15.8 \mathrm{mM}, \mathrm{pH} 7.0$; for the homogeneous Fenton: MO concentration $=50 \mathrm{mgl}^{-1},\left[\mathrm{Fe}^{3+}\right]=0.46 \mathrm{gl}^{-1}, \mathrm{H}_{2} \mathrm{O}_{2}$ concentration $=15.8 \mathrm{mM}$, and $\mathrm{pH} 7.0$.

example, Zhang and Ma [20] reported $\alpha-\mathrm{FeOOH}$ (goethite) formed in the similar reaction scopes. The stability of amorphous $\mathrm{FeOOH}$ supported on the acidized fly ash can be attributed to the reasons discussed below.

During the process of preparation, the fly ash contacted with the acidic solution firstly, and $\mathrm{Si}-\mathrm{O}$ bond on the surface of the spherical glassy particles increased due to dissolution of the metal elements. Afterwards, when $\mathrm{FeOOH}$ precipitated from the aqueous solution and coated on the surface of the residual fly ash, Fe-Si surface complex (typically, $\mathrm{Fe}-\mathrm{O}-\mathrm{Si}(\mathrm{OH})_{3}$ ) formed in situ as reported in the previous literatures [21,22], hence blocked or retarded the transformation of initially formed $\mathrm{FeOOH}$ to crystalline iron oxides such as ferrihydrite, goethite and hematite.

\subsection{Influence of the homogeneous Fenton}

Undoubtedly, the leached iron is generated at lower $\mathrm{pH}$ (below 4.0) due to the reductive dissolution of $\mathrm{FeOOH}$ [4] and consequently, it can assist the Fenton reaction even in the heterogeneous system. Besides $\mathrm{pH}$, the concentration of leaching iron varies by the irradiation time, concentration of $\mathrm{H}_{2} \mathrm{O}_{2}$ and catalyst dosage [23].

To understand whether dissolved iron from the catalyst would contribute significantly to the decomposition of MO, the dissolved iron concentration was measured in one of the heterogeneous Fenton experiments. In the presence of $2.5 \mathrm{~g} \mathrm{l}^{-1}$ catalyst (theoretically $0.46 \mathrm{~g} \mathrm{Fe}^{-1}$ ) and $15.8 \mathrm{mM} \mathrm{H}_{2} \mathrm{O}_{2}$ at initial $\mathrm{pH} 7.0$, the photocatalytic decomposition rate of $\mathrm{MO}$ was nearly $99 \%$ after 60 min reaction (Fig. 6) and the highest leaking iron concentration within $120 \mathrm{~min}$ measured was $0.26 \mathrm{mgl}^{-1}$, which was quite below the max leaking value of $0.95 \mathrm{mgl}^{-1}$ reported for $\alpha$-FeOOHR Fenton system with the similar iron dosage $\left(5 \mathrm{gl}^{-1} \alpha\right.$-FeOOHR and theoretically $0.5 \mathrm{~g} \mathrm{Fe}^{3+} \mathrm{l}^{-1}$ ) and the initial reaction $\mathrm{pH}$ (7.47) [23]. This was mainly ascribed to the following two reasons. One was that the leached iron species may quickly hydrolyze and age relative quickly to more stable (less soluble) particulate iron oxyhydroxides forms at $\mathrm{pH} 7.0$. Another was that the amorphous FeOOH supported on acidized fly ash was intrinsically stable (above mentioned) and not easy to dissolve into the solution, thus the dissolved iron concentration was very low in this system. Moreover, the leaching iron concentration was well below the EU directives, which allow a maximum of $2 \mathrm{mg} \mathrm{l}^{-1}$ in the treated water to be discharged directly into the environment. 
The control homogeneous Fenton experiments (using $0.26 \mathrm{mg} \mathrm{Fe}^{3+} \mathrm{l}^{-1}$ as Fenton reagent) were arranged with and without UV light. The results are shown in Fig. 6. The traditional homogeneous Fenton without UV irradiation, the removal of MO of $20 \mathrm{~min}$ attained $6 \%$, and as the irradiation time extended to $180 \mathrm{~min}$, no evident change of the removal was observed and the removal kept stable unlike the fluctuation of removal of MO in heterogeneous Fenton which was due to adsorption (Fig. 2(a)).

When UV irradiation was used, the catalytic performance of the homogeneous Fenton enhanced, nevertheless, it was less than that of heterogeneous photo-Fenton process. The removal of MO at this level of dissolved iron concentration was about $60.8 \%$ after 60 min reaction while that of heterogeneous photo-Fenton process was $96.4 \%$. Until the irradiation time extended to $180 \mathrm{~min}$, the removal of the homogeneous Fenton system with UV irradiation can also attain $97.8 \%$, indicating that the irradiation time of the heterogeneous Fenton was nearly 120 min less than that of the homogeneous Fenton when MO was completely decolored.

\section{Conclusions}

Through dissolution and precipitation processes using a high iron-containing fly ash as the raw material, amorphous $\mathrm{FeOOH}$ was successfully loaded on the surface of residual ash after acidized, and used as the catalyst in UV-Fenton system for the degradation of MO. The mesoporous structure of $\mathrm{FeOOH}$ provided a wide contact interface between the catalyst and the MO molecules, and accelerated the heterogeneous Fenton process. The catalyst exhibited a high catalytic activity and almost $100 \%$ discoloration of $50 \mathrm{mg} \mathrm{l}^{-1}$ MO could be obtained at 80 min reaction even if the initial $\mathrm{pH}$ of solution was as high as 9.0, so the catalyst enabled operation at around the neutral and alkaline solution. Moreover the catalyst was of great importance for application due to its good stability, easy physical solid-liquor separation, little iron leaching and no need to be regenerated.

\section{Acknowledgements}

This work was financially supported by the National Key Technology R\&D Program (2008BAC32B03), the National Basic Research Program (2007CB407303) and the National Water Pollution Control Program (2008ZX07012-002-004) of China.

\section{References}

[1] F.J. Rivas, F.J. Beltrán, J. Frades, P. Buxeda, Oxidation of p-hydroxybenzoic acid by Fenton's reagent, Water Res. 35 (2001) 387.
[2] J. He, W. Ma, J. He, J. Zhao, J.C. Yu, Photooxidation of azo dye in aqueous dispersions of $\mathrm{H}_{2} \mathrm{O}_{2} / \alpha-\mathrm{FeOOH}$, Appl. Catal. B: Environ. 39 (2002) 211.

[3] J.J. Wu, M. Muruganandham, J.S. Yang, S.S. Lin, Oxidation of DMSO on goethite catalyst in the presence of $\mathrm{H}_{2} \mathrm{O}_{2}$ at neutral pH, Catal. Commun. 7 (2006) 901.

[4] S. Chou, C. Huang, Y.-H. Huang, Heterogeneous and homogeneous catalytic oxidation by supported $\gamma$-FeOOH in a fluidized-bed reactor: kinetic approach, Environ. Sci. Technol. 35 (6) (2001) 1247.

[5] X. Wang, C. Liu, X. Li, F. Li, S. Zhou, Photodegradation of 2mercaptobenzothiazole in the $\gamma-\mathrm{Fe}_{2} \mathrm{O}_{3}$ /oxalate suspension under UVA light irradiation, J. Hazard. Mater. 153 (2008) 426.

[6] J. Chen, L. Zhu, UV-Fenton discolouration and mineralization of orange II over hydroxyl-Fe-pillared bentonite, J. Photochem. Photobiol. A: Chem. 188 (2007) 56.

[7] B. Iurascu, I. Siminiceanu, D. Vione, M.A. Vicente, A. Gil, Phenol degradation in water through a heterogeneous photo-Fenton process catalyzed by Fe-treated laponite, Water Res. 43 (2009) 1313.

[8] C.-L. Hsueh, Y.-W. Lu, C.-C. Hung, Y.-H. Huang, C.-Y. Chen, Adsorption kinetic, thermodynamic and desorption studies of C.I. Reactive Black 5 on a novel photoassisted Fenton catalyst, Dyes Pigments 75 (2007) 130.

[9] J.H. Ramirez, F.J. Maldonado-Hódar, A.F. Pérez-Cadenas, C. Moreno-Castilla, C.A. Costa, L.M. Madeira, Azo-dye Orange II degradation by heterogeneous Fentonlike reaction using carbon-Fe catalysts, Appl. Catal. B: Environ. 75 (2007) 312.

[10] B. Muthukumari, K. Selvam, I. Muthuvel, M. Swaminathan, Photoassisted hetero-Fenton mineralisation of azo dyes by $\mathrm{Fe}(\mathrm{II})-\mathrm{Al}_{2} \mathrm{O}_{3}$ catalyst, Chem. Eng. J. 153 (2009) 9.

[11] J.R. Domínguez, J. Beltrán, O. Rodríguez, Vis and UV photocatalytic detoxification methods (using $\mathrm{TiO}_{2}, \mathrm{TiO}_{2} / \mathrm{H}_{2} \mathrm{O}_{2}, \mathrm{TiO}_{2} / \mathrm{O}_{3}, \mathrm{TiO}_{2} / \mathrm{S}_{2} \mathrm{O}_{8}{ }^{2-}, \mathrm{O}_{3}, \mathrm{H}_{2} \mathrm{O}_{2}, \mathrm{~S}_{2} \mathrm{O}_{8}{ }^{2-}$, $\mathrm{Fe}^{3+} / \mathrm{H}_{2} \mathrm{O}_{2}$ and $\mathrm{Fe}^{3+} / \mathrm{H}_{2} \mathrm{O}_{2} / \mathrm{C}_{2} \mathrm{O}_{4}{ }^{2-}$ ) for dyes treatment, Catal. Today 101 (2005) 389.

[12] Y. Li, F.-S. Zhang, R.-X. Fu, Arsenic (V) removal from aqueous system using adsorbent developed from a high iron-containing fly ash, Sci. Total Environ. 407 (2009) 5780.

[13] M.J. Liou, M.-C. Lu, Catalytic degradation of explosives with goethite and hydrogen peroxide, J. Hazard. Mater. 151 (2008) 540.

[14] V. Kavitha, K. Palanivelu, The role of ferrous ion in Fenton and photo-Fenton processes for the degradation of phenol, Chemosphere 55 (2004) 1235.

[15] L.G. Devi, S.G. Kumar, K.M. Reddy, C. Munikrishnappa, Photo degradation of Methyl Orange an azo dye by advanced Fenton process using zero valent metallic iron: influence of various reaction parameters and its degradation mechanism, J. Hazard. Mater. 164 (2009) 459.

[16] C.-L. Hsueh, Y.-H. Huang, C.-C. Wang, C.-Y. Chen, Photoassisted fenton degradation of nonbiodegradable azo-dye (Reactive Black 5 ) over a novel supported iron oxide catalyst at neutral pH, J. Mol. Catal. A: Chem. 245 (2006) 78.

[17] C. Catrinescu, C. Teodosiu, M. Macoveanu, J. Miehe-Brendle, R.L. Dred, Catalytic wet peroxide oxidation of phenol over Fe-exchanged pillared beidellite, Water Res. 37 (2003) 1154.

[18] C. Galindo, P. Jacques, A. Kalt, Photodegradation of the aminoazobenzene acid orange 52 by three advanced oxidation processes: $\mathrm{UV} / \mathrm{H}_{2} \mathrm{O}_{2}, \mathrm{UV} / \mathrm{TiO}_{2}$ and $\mathrm{VIS} / \mathrm{TiO}_{2}$ : comparative mechanistic and kinetic investigations, J. Photochem. Photobiol. A: Chem. 130 (2000) 35.

[19] J. Fan, Y. Guo, J. Wang, M. Fan, Rapid decolorization of azo dye Methyl Orange in aqueous solution by nanoscale zerovalent iron particles, J. Hazard. Mater. 166 (2009) 904.

[20] T. Zhang, J. Ma, Catalytic ozonation of trace nitrobenzene in water with synthetic goethite, J. Mol. Catal. A: Chem. 279 (2008) 82.

[21] P.J. Swedlund, J.G. Webster, Adsorption and polymerisation of silicic acid on ferrihydrite and its effect on arsenic adsorption, Water Res. 33 (1999) 3413.

[22] F.-S. Zhang, H. Itoh, Iron oxide-loaded slag for arsenic removal from aqueous system, Chemosphere 60 (2005) 319.

[23] Y. Zhao, J. Hu, Photo-Fenton degradation of $17 \beta$-estradiol in presence of $\alpha$ FeOOHR and $\mathrm{H}_{2} \mathrm{O}_{2}$, Appl. Catal. B: Environ. 78 (2008) 250. 